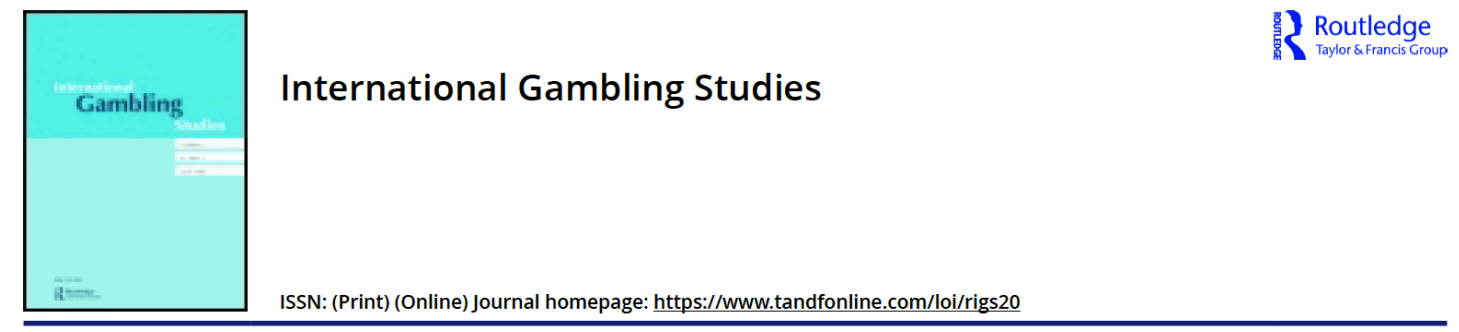

\title{
The utilization and perception of sports betting experts ('tipsters') among sports bettors with gambling problems: a qualitative focus group interview study
}

\author{
Hibai Lopez-Gonzalez , Alicia Rius-Buitrago, Susana Jimenez-Murcia \& Mark \\ D. Griffiths \\ To cite this article: Hibai Lopez-Gonzalez , Alicia Rius-Buitrago, Susana Jimenez-Murcia \& Mark \\ D. Griffiths (2020): The utilization and perception of sports betting experts ('tipsters') among sports \\ bettors with gambling problems: a qualitative focus group interview study, International Gambling \\ Studies, DOI: 10.1080/14459795.2020.1844270 \\ To link to this article: https://doi.org/10.1080/14459795.2020.1844270
}

\begin{abstract}
Tipsters are sports betting experts that offer recommendations concerning betting opportunities, usually in exchange for money. With the growth of online sports betting, tipsters have become more accessible via social media. However, it remains unknown whether tipsters might have an impact on sports bettors experiencing gambling problems. In the present study, data concerning tipsters were collected via focus group interviews with sports bettors undergoing treatment for gambling disorder $(n=28)$ and examined utilizing a thematic analysis approach. The findings suggest that many participants used tipsters during their gambling activity, although they had divergent thoughts about their actual ability to produce accurate tips. The selection of tipsters appears to be biased towards personal contact and word-of-mouth strategies rather than objective performance data. Notably, many bettors had experienced thoughts of becoming tipsters themselves. The participants struggled to integrate into a coherent narrative both the existence of individuals such as tipsters who (allegedly) have been able to consistently 'beat the bookies', and their contrasting personal experience of repeated losses. This has
\end{abstract}


implications for therapists working on cognitive restructuring, because tipsters made sports bettors wonder about the importance of skill in betting, and whether thinking they could be winners was actually a distorted or a realistic perception.

Keywords: gambling disorder; sports betting; cognitive distortions; tipsters; sports betting experts; professional gamblers; focus group interviews

\section{Introduction}

The sports betting industry deploys considerable resources to make the general public think that they can 'beat the bookies' based on their own betting skills, sports knowledge, analytical ability, and experience (Hing et al., 2017; Newall, 2018). Sports betting narratives that enhance the importance of skill over chance are not solely generated by their advertising imagery (Lamont et al., 2011), but are a product of media sport affiliates that discuss betting prospects in their articles and shows, fantasy leagues, VIP schemes, betting leagues and tournaments, and the interaction of sports betting with trading, forex investment, and poker sites (Lopez-Gonzalez \& Griffiths, 2018). The focus on skill-based gambling arguably creates a subsidiary gambling industry that caters for the needs it generates: more knowledge, analytical tools, training, and statistical models. Consequently, expertise in sports has become a commodity. All in all, such 'gambling establishment' - to use Orford's term (2020) - arguably produces and reproduces a discourse focused on skill that entices new consumers with the promise of winning money.

This subsidiary gambling industry includes 'tipsters', who advertise themselves as suppliers of insights to optimise decision-making in betting. Tipsters are a new addition 
in many sports betting markets, particularly those that have little tradition of horse racing (Deschamps \& Gergaud, 2008). A tipster is 'a person who gives information (tips) to other people, usually in exchange for money, especially about the likely winner of a race or competition' (Cambridge Online Dictionary, n.d.). Most tipsters - excluding those that serve as brand ambassadors for bookmakers such as former footballers and renowned sports journalists (Lopez-Gonzalez \& Tulloch, 2015) - try to 'beat the bookies' exploiting inefficiencies in their forecasts and finding 'value' in mispriced odds.

Tipsters have to be differentiated from 'insiders', who might beat the bookies by using information not publicly available or match-fixing, that is, illegally. With the popularisation of digital social media and online gambling, online tipsters have proliferated, who typically sell their tips for a monthly fee in exchange for a previously agreed upon number of tips. Tipsters use sports knowledge, gambling skills, and analytical capacity (nowadays often assisted by algorithms and statistical models) to identify hidden betting opportunities. The reason why tipsters sell this information instead of acting on it is because bookmakers allegedly restrict or ban sports bettors who systematically obtain positive returns (Cook, 2018). Professional tipsters can be viewed as investment analysts, and as such, they might become role models for amateur bettors to emulate. Alongside the rise of tipsters, a black market of questionable tipping practices and predatory tactics has emerged. Some tipsters give contrasting tips to different customers, and others recommend bets likely to lose to pocket a $30 \%$ commission from losses incurred in affiliate betting sites (Busby, 2017).

Whether tipsters can actually beat the bookies in the long run is a matter of controversy. Some studies have found evidence of the effectiveness of tipsters in beating the odds. 
Despite most football betting markets being efficient (i.e., the odds reflect the real probability of the events and bookmakers cannot be systematically beaten), some markets appear to be inefficient and show favourite-longshot biases (i.e., the odds of favourites are undervalued), which can be exploited by professional tipsters, even after factoring in the house edge (Angelini \& De Angelis, 2019). Similar strategies using the implied probability given by bookmakers (i.e., their odds) and averaging these odds across many bookmakers, also may find positive returns in the long run (Kaunitz et al., 2017).

Other studies have found mixed results regarding the efficacy of tipsters. One study investigating the predictions of online tipsters found that their average aggregate results over 68,339 bets outperformed the results of individual tipsters, with a combined return of $1.317 \%$ (Brown \& Reade, 2019). This study was a demonstration of 'the wisdom of the crowd', that is, individual tipsters' predictions might deviate from optimal performance but the mean average of such predictions is highly accurate (Brown \& Reade, 2019).

However, a number of empirical studies have reported evidence that casts doubt on the effectiveness of tipsters. A study carried out over three German Bundesliga football (soccer) seasons concluded that betting odds were better predictors than tips from experts, and that even with bookmaker commissions down to zero they lagged behind $-0.19 \%$ (Spann \& Skiera, 2009). Similarly, statistical models generated to outperform bookmakers in the English Football Premier League were incapable of producing consistent positive returns and found no evidence of market inefficiency (McCracken, 2014). Although tipsters appear to perform better than random models (Forrest \& 
Simmons, 2000), they still cannot systematically outperform odds set by bookmakers (Forrest et al., 2005).

\section{Tipsters, skill, and problem gambling}

Data from multiple territories generally agree that opportunities for skill-based (also known as strategic) gambling is increasing while chance-based (i.e., non-strategic) gambling is in decline (Delfabbro et al., 2020), mainly because younger generations systematically show preference for skill-based gambling and find pure chance games less attractive. A study investigating the gambling mode preference of UK gamblers from 2000 to 2015 found that poker and sports betting had become much more common over the period of investigation (Sharman et al., 2019). This trend has also been observed among a representative sample of regular gamblers from Australia, in which the authors concluded that because skill games are comparatively more consumed by males, they view such games as outlets to express their dominance and knowledge (Stevens \& Young, 2010).

Sports bettors in recovery struggle to understand the role that chance played in their betting history and wonder if they would have become successful bettors had they not lost control due to a gambling disorder (Lopez-Gonzalez et al., 2020). During their treatment, cognitive-behavioural therapy - the 'gold standard' for gambling disorder (Petry, 2016) - tries to restructure gamblers' thoughts about luck and skill, but new sports betting forms put into question some long-held truths such as the house edge (Woolley et al., 2013) and the illusion of control (Langer, 1975). Sometimes skill-based forms might be designed in a way that a small percentage of the gamblers obtain benefits (e.g., sports betting exchange markets) (Delfabbro et al., 2020), potentially making sports bettors 
think that they are not falling victim to erroneous cognitions. Cognizant of the consumers' appetite for skill games and agency, the gambling industry commercializes products that vastly exaggerate the actual control gamblers can exert in them and underestimates their randomness (Lopez-Gonzalez et al., 2018; Newall, 2018).

Some scholars have argued that skill-based gambling merits special attention because it might capitalise on distorted cognitions more prominently than chance-based gambling (Toneatto et al., 1997). In this sense, a study conducted with Canadian undergraduate students showed that online gamblers (more likely to engage in skill-based games) had a higher degree of cognitive distortions as compared to offline gamblers (MacKay \& Hodgins, 2012). Furthermore, gamblers with a preference for skill games had a greater illusion of control than those preferring chance games or a combination of both (Myrseth, Brunborg, \& Eidem, 2010). Similarly, another study reported that gamblers involved in skill games saw themselves as having higher levels of personal luck (Wohl, Young, \& Hart, 2005). The authors argued that skill-based games might 'prime' gamblers' underlying cognitive structure, and activate self-schemas of being lucky. However, a more recent study did not find differences in gambling-related cognitions between skillbased gamblers and chance-based gamblers (Challét-Bouju et al., 2016).

\section{The present study}

This study scrutinises the role of tipsters in the context of online sports bettors that have experienced problems with their gambling behaviour. By means of a qualitative analysis of the discourse of sports bettors undergoing treatment for gambling disorder, the study examines how useful sports bettors consider tipsters were, their use of tipsters in the past, their ideation of becoming tipsters themselves, and their overall views of the sports 
betting tipsters' market. The study explores how the existence of tipsters might have interacted with the development of their gambling disorder and their perceived chances of winning. It should also be noted that this study does not consider whether tipsters directly affected the onset of gambling problems. Instead, it examines if having visible examples of success in beating the bookies - tipsters supposedly make money thanks to their gambling skills - might alter the way gamblers think about sports betting and the possibility of winning money, with implications for resuming gambling and relapsing. To the best of our knowledge, this is the first study to empirically examine the role of sports betting tipsters in the context of problem gambling.

The analysis of tipsters presented in this paper is part of a larger research project covering the impact of new internet-based characteristics (e.g., in-play betting, cash out features, mobile gambling) on online gamblers undergoing treatment for gambling disorder. The original study design did not comprise the topic of tipsters, and was only introduced at a later stage once the preliminary data analysis identified it as something relevant for participants. The Method section below details the followed procedure.

\section{Method}

\section{Sample and procedure}

Six focus groups were conducted in different Spanish cities from March to June 2019. The average length of the group interview was 73 minutes. In total, 40 online gamblers undergoing cognitive-behavioural therapy for gambling disorder participated in the discussions. The diagnosis was based on the Spanish version of the DSM-IV criteria for pathological gambling (Jiménez-Murcia et al., 2009) and was independently confirmed 
via an individual interview with a clinical psychologist. All participants were selfexcluding from gambling at the time of the interviews, and reportedly, in abstinence.

The sample was part of a broader interview schedule about online versus offline gambling differences in treatment-seeking patients, but for the purpose of the present study, only data selected from the online sports bettors among them is reported here $(n=28)$. All of the sports bettors were males. They had a mean age of 32 years $(\mathrm{SD}=6.6)$, and reported a mean age of gambling onset at 22.7 years $(\mathrm{SD}=7.1)$. All but one of the participants were employed. Regarding education, 11 out of 26 had vocational/technical training (39.3\%), nine had university-level education (32.1\%), six had completed secondary education $(21,4 \%)$, and two dropped out of school (7.4\%). More detailed information about participants is available in Supplementary File 1.

The participants were recruited via a non-probabilistic purposive sampling. The first author contacted the Spanish Federation of Rehabilitated Gamblers (Federación Española de Jugadores de Azar Rehabilitados [FEJAR]), a large organisation that provides assistance nationwide to people experiencing gambling problems. In the email to the FEJAR, it was mentioned that participants had to be diagnosed with gambling disorder, be adults (i.e., be aged 18 years or older), and used the internet as their main gambling channel. All prospective participants who reported back to the research team and met the inclusion criteria were included in a focus group to be carried out at their local treatment facility. The first author (a male $\mathrm{PhD}$ ) travelled to conduct the discussion groups on site. The research team are not aware of how many FEJAR patients met the inclusion criteria but who declined to participate or why. All of the participants were informed about the topic and goals of the study. The research team and the participants 
were not previously acquainted and therefore no biases were perceived to interfere. No field notes were taken and the participants received no feedback about the results of the study. Except in one case, no individuals apart from the first author were present during the focus group. The focus groups were conducted in Spanish, and the quotes as well as the interview guide reported in this paper were translated into English by the research team, which includes native speakers of Spanish and English language. The discussions were audiotaped and later transcribed by another member of the research team.

\section{Ethical and reporting standards}

Prior to the study, the first author's institution's research committee at the time of the study approved it (Ref: ETK-38/18-19). The participants were informed of their rights and that abandoning the study would have no consequences for their treatment. They signed consent forms and received $€ 10$ headphones in exchange for their collaboration. The present study strictly follows the reporting guidelines outlined in the Consolidated Criteria for Reporting Qualitative Research (COREQ) and its 32-item checklist for focus group studies (Tong et al., 2007), as recommended by the EQUATOR Network. This checklist promotes transparency and replicability in reporting qualitative data.

\section{Analytical approach and data analysis}

The focus group data gathering technique allowed the first author to create a safe environment for bettors in recovery to talk and discuss their betting practices among peers who endured similar experiences and to whom they were already acquainted. The focus group format facilitates the dynamic exchange of views and, contrary to semi-structured one-on-one interviews, they promote the spontaneous intervention of participants to agree, clarify, delimitate, or oppose other participants' opinions (Wilkinson, 2004). This 
is especially relevant in the context of sports betting, a gambling activity social in nature, often carried out in the company of peer bettors and sport fans (Deans et al., 2017; Gordon \& Chapman, 2014). Once the data were collected, a thematic analysis approach was used to facilitate the emergence of themes from the discourse.

The research team had drafted a brief script comprising six blocks for the focus groups. However, the topic of 'tipsters' that forms the topic of the present paper was not part of the original draft of the interview script. The topic of 'tipsters' emerged later during the preliminary analysis of the first interviews, because the explorative and iterative nature of the qualitative research and its analysis allows for this type of changes 'on-the-go' (Creswell, 2014). Once the topic emerged, the script was complemented with follow-up questions to understand the implications of tipsters for gamblers in recovery (see Supplementary File 2).

The content of the focus groups was analysed with NVivo 11 for Mac. The first author did the preliminary coding and two other authors did successive rounds of re-coding, discussing with the first author the emerging themes. There were two main coding cycles based on Saldaña's (2009) theory of coding. In the first cycle, a holistic coding was performed to outline the main themes discussed by participants (see Supplementary File 3). The first author tried not to replicate the blocks that guided the conversation, being open to identifying new themes that were not anticipated by the literature review. Once the theme of 'tipsters' became clear to the research team, a second cycle of analysis was conducted in which a structural coding was used to specifically look for the connections of the concept of tipsters with other nodes that were not addressed in the first round of 
coding. In this second round, an effort was made to merge codes into bigger categories, something equivalent to the pattern coding proposed by Saldaña (2009).

\section{Results}

Eighteen sports bettors (69.3\%) reported having used the services of tipsters at some point during their gambling, whereas ten $(35.7 \%)$ said they never used them. Among those who did use them, participants were approximately equally split between those who thought that tipsters worked and helped them secure positive results and those who thought they were useless. In general, participants were not able to clearly distinguish their own betting decisions from decisions recommended by tipsters, resulting in a very vague recollection of the real effect tipsters had on their betting record over time.

Four major themes emerged from the second cycle of coding of tipster-related material. First, reasons why bettors did not like tipsters' services or did not use them [Theme 1]. Second, the reasons for supporting the use of tipsters, how to identify good ones, and how their business model works [Theme 2]. Third, the self-image of sports bettors as knowledgeable in sports and their thoughts about becoming professional tipsters themselves [Theme 3]. Fourth, the way gambling disorder impacted their relationship with tipsters and the use bettors made of the tips [Theme 4]. These themes are narratively summarised in Figure 1 - replicating a flowchart - to capture the mental process of the participants.

Insert Figure 1 about here

Why some sports bettors think tipsters do not work (Theme 1) 
Regarding the first theme, a few participants thought tipsters served no purpose in the sports betting field and that "now every sports bettor thinks they can become a tipster" (P34, Sevilla, 26 years). Participants 11, 12, 13, 14, and 31 reported having signed up in Telegram (an instant messaging service) to follow tipsters' groups but never paid for any subscription-based tipster account. Participant 37 had trouble in providing a balanced account of his experience with tipsters and relied heavily on recalls in which the tips he bought lost him the opportunity of winning an aggregate bet (i.e., he had guessed multiple results on his own but failed to complete the overall bet because the one result obtained via a tipster was erroneous). Participant 33 was particularly belligerent towards tipsters, to whom he referred as 'scams'. He mentioned being a member of a Telegram group called Comando Estafa [Commando Scam] in which users told their negative experiences subscribing to tipsters and how the vast majority of these had no differential skill over a regular sports bettor. He explains how, in his opinion, tipsters' scams work and how anybody had the capability to produce one:

"Do you know what a good business looks like? Here is a good business. Look, you put 6500 in ads for Instagram and Facebook, you select five or ten good screenshots of big bets that have gone your way and that's it, that's a pretty good business because you're cheating lots of people. You're going to get 50, 100, 500 people that you're going to charge for your tips" (P33, Sevilla, 27 years).

\section{Why some other sports bettors like/use tipsters (Theme 2)}

A larger group of participants thought tipsters worked. Participants delved deeper into the reasons why some tipsters were perceived as a better deal than others and how they made up their mind about the efficacy of tipsters. Even though many websites keep track of 
tipsters' betting records, which could be considered an objective way of differentiating good tipsters from bad, the participants here did not appear to resort to such data to inform their purchasing decision and engaged in more biased and subjective decision-making processes.

One such process was using the price of the service as an indicator of the quality of the tipster. Most of the participants reported either having used free tipsters, to whom no money was transferred, or relatively affordable tipsters with monthly fees in the range of $€ 15$ to $€ 40$. A fee of $€ 20$ per month appeared to be the most reported amount among participants. Some of these subscription-based tipsters provided a mixed model of free tips that everybody could receive and paid tips that were only for subscribers, equivalent to a freemium model in which the subscriber decides the extent of their commitment to the product. According to some participants, in these freemium models, free tips were usually more infrequent - one tip every two or three days - whereas paid tips were delivered on a daily basis, usually three or four a day, and contained potentially larger payoffs with riskier odds and more sophisticated data analysis. One participant (P22, Oviedo, 26 years) admitted to paying $€ 200$ to a tipster along with some friends. Another participant (P10, A Coruña, 39 years) reported having spent as much as $€ 500$ in hiring a tipster from Ukraine but he felt confused about the true nature of this transaction because it was highly likely that this was a case of insider information (i.e., match-fixing) rather than tipping.

Word-of-mouth recommendations appeared to be very important. Almost all participants who used tipsters hired a friend or the 'friend of a friend', and even when they hired somebody unknown to them, it was through a personal recommendation from a friend or 
work colleague. The only participant who hired someone from a pool of verified tipsters felt confident about it:

"These are paid tipster services, let's say, 'safe'. They provide you with their betting record. You can check their record... they provide you a real benefit, you pay a monthly fee and they give you the tips" (P30, Oviedo, 26 years).

However, this was not the norm. A particularly pervasive index of tip quality was the standard of life tipsters were able to have - or at least show. Almost all participants appeared to be capable of retrieving from memory episodes of tipsters showing off how much money they had made. One participant remembered the story of a tipster from London who supposedly made $£ 60,000$ a year in sports bets and how he wanted to emulate his success by working harder in his study of the game.

"I'll tell you something. Maybe you heard it on the radio [as I did]. There is a guy from London who made €60,000 [annually]. He was an expert. He must have been. But I was a football coach, and every time I watched a game a checked if starters were playing, the likelihood of a draw... It was a nightmare, [because] after all the time I spent, I didn't win, and I said to myself, this guy must be really a genius, he must be 24 hours a day analysing” (P38, Leganes, 44 years).

In the same focus group, another participant (P40, Leganés, 35 years) recalled seeing a tipster friend amassing money from his tips to invest all of it in a single $€ 100,000$ bet on Real Madrid becoming the winner of the UEFA Champions League final. He made $€ 20,000$ in that bet and the participant was witness to it, leaving a vivid impression on 
him. Similarly, the next excerpts are illustrative examples of the significance of an opulent image to convey the notion of success. In these cases, success is represented by the ownership of good cars:

"I was studying for my certificate of higher education in the automotive industry with this kid. He became a tipster for online sports betting, bought a new [Volkswagen] Tiguan, dropped out of school and he's living out of his tips, making incredible money" (P33, Sevilla, 27 years).

"This guy was making a shitload of money from four imbeciles like myself. In fact, he was 22 years-old, he was sending videos driving amazing cars and you were like...I mean, just do the math, $€ 20$ per imbecile, he is making $€ 6000$ [a month]" (P2, Vigo, 29 years).

However, the ultimate confirmation of the quality of a tipster came when a large bookmaker offered the tipster to break ranks and join them as an employee. Although participants did not have a means to know for sure which tipsters - if any - were offered this opportunity, this narrative of the tipster-turned-bookie appeared to pervade the perception of participants. Not coincidentally, as will be observed in Theme 3, a few participants reported having been contacted by bookmakers or having been approached by somebody close to bookmakers, interpreting such contacts as proof of their ability in sports betting.

In general, participants who hired tipsters felt ambivalent about their real efficacy but were reluctant to entirely dismiss them as a fraud, as illustrated in the next excerpt: 
"Researcher: But do you think that, if you limited yourself to betting on the recommendations made by tipsters, you'd win money?

P22: See, I think they all are 'vendehumos' [difficult to translate: literally, someone who sells smoke, a fraudster and a chatterbox], but well, there are some that have some knowledge, some information, or things that can help you" (Oviedo, 26 years).

Here, the participant was able to combine in the same sentence (i) the assertion that all tipsters oversell their product and exaggerate, while at the same time (ii) limiting the scope of the assertion to some tipsters or some occasions.

\section{Self-image of sports bettors as experts (Theme 3)}

The third theme dealt specifically with the self-perception of bettors undergoing treatment as tipsters. Because all of the participants were highly engaged sports bettors, most of them had considered at some point the idea of becoming professional tipsters. This was particularly crucial for participants who had trouble reconciling two ideas: on the one hand, their self-perceived efficacy as sports bettors; and on the other hand, their huge debt from gambling. The following example epitomizes the internal conflict of some bettors in recovery that cannot integrate their betting losses into a coherent personal narrative that preserves them as knowledgeable sport fans. For this participant, betting was financially disastrous because of his inability to manage money and, precisely for this reason, becoming a tipster would have been an ideal solution as seen evidenced in the next two excerpts: 
"Our problem resides in the lack of control [as opposed to insufficient sport knowledge]. Obviously, nobody would ever say 'hey, you wanna be a tipster with us?' if it wasn't for my record. They contact you because they saw your record. A guy who had worked for [British online betting operator] Bet365 offered me a job. He told me 'I've seen your last year's table tennis results'...Knowing what I know now, that would have been my dream job ten years ago, gambling without my own money and getting a salary every month. [...] In my hometown I was running a WhatsApp group with twenty participants, I got $10 \%$ of everything they won. I should have stopped there. It wasn't a monthly fee. They told me 'here are $€ 50$, move them around'. And I just bet them and kept 10\% of the profits. I bet with money that wasn't mine. That's why I keep telling you, if I wasn't a good bettor they wouldn't have asked me to do it" (P32, Sevilla, 42 years).

A few more bettors reported having been contacted by tipsters and asked if they would like to join them, something that most interpreted as testament to their betting skills. When confronted about the possibility that those might have been tipster tactics to increase their loyalty and keep them paying the subscription, none of the participants thought that was likely.

Some sports bettors in the study thought during the course of their betting history that they could sell their sports knowledge to others or act on it themselves by becoming professional sports bettors. One participant (P28, Oviedo, 35 years) admitted having paid other bettors in exchange for their username and password so that he and his friend could bet under a false identity. This behaviour can only be understood during the first period of their betting history, when bettors might still be net winner and believe they can 
professionalise their hobby. At that time, bookmakers might have shut down or restricted the account of some bettors if they consistently won more than they lost. This is why betting accounts with losing records are especially attractive for bettors wanting to become professional gamblers because bookmakers would typically keep these open.

\section{Gambling disorder affecting how bettors perceive tipsters (Theme 4)}

The fourth theme concerned the role of bettors undergoing treatment for gambling disorder and how that influenced their interpretation of the efficacy of tipsters. In general, many participants considered their gambling disorder as a condition that prevented them from objectively assessing the ability of tipsters to produce accurate tips. A few (e.g., P37) acknowledged paying for tips but not even using them for no apparent reason. Others (e.g., P34) tried to adhere to the recommendations but were incapable of doing so - by the time they received the tips their balance was down to zero. What appeared to be a more common issue with tips was that, while a few participants (e.g., P2) followed them to the letter, most were unable to refrain from gambling further. The vast majority of bettors in the study acknowledged they bet more money than what was recommended to them by tipsters. This situation left them thinking that tipsters might as well work and be useful, but because they are problem gamblers they cannot take advantage of it. In the next excerpt, one sports bettor reflected on the impossibility of adhering to recommendations once gambling disorder begins:

"I began betting because some friends had hired a tipster, they started with this really good tipster and I joined them...for a while, then I reckon this illness makes you lose control, you begin betting of your own accord, by yourself, on games that 
make no sense, totally random stuff and that's when things go downhill" (P22, Oviedo, 26 years).

One participant (P30, Oviedo, 26 years) reported hiring a tipster as a way to chase his losses once his debt had become uncontrollable. This strategy was considered to be reasonable (i.e., a way of returning to more analytical, planned bets with less improvisation and in-play betting stamina). Nevertheless, only this participant reported this behaviour and said it only happened for a limited period of time.

Some participants commented on the possibility that some tipsters might have developed a gambling disorder themselves given the amount of time and money they devoted to engaging in gambling activities. One participant reflected on how tipsters might be fundamentally similar to sports bettors in treatment, but with the capacity to identify and prevent the onset of gambling disorder:

"This friend of mine, he was very aware of gambling disorder, he has read a lot about it, and knew very well how to avoid reaching that point where gambling really affects you” (P30, Oviedo, 26 years).

\section{Discussion}

The present study explored the role that tipsters play in the context of sports betting and problem gambling. The findings reported here provided evidence concerning how bettors undergoing treatment for gambling disorder interacted with tipsters, the extent they used their services, how they assessed them, and the way the existence of tipsters might 
interfere in the recovery of bettors and the restructuring of their perceptions about skill and the probability of winning.

Sports bettors in treatment were familiar with tipsters and just less than two-thirds of them had hired their services at some point during their gambling history. Considering that bookmakers in the country do not have official platforms that showcase for-hired tipsters, it means that sports bettors resort to unofficial channels, ostensibly not associated with bookmakers, to locate and contact tipsters. Consequently, bettors may become more exposed to scams and frauds (Busby, 2017), and are compelled to navigate through dozens of websites, blogs, and third-party bet aggregators (e.g., www.thebetinvestor.com) that promise reliable information but respond to no authority or regulator who oversee them. Perhaps as a result of this uncertain landscape, the interviewed sports bettors appeared to rely more on personal recommendations and 'word-of-mouth' to hire tipsters, and once they hired them, the loss of control inherent to the development of gambling disorder made them unable to give a proper assessment of the effectiveness of tipsters.

The fact that 'tipster' emerged as a theme in this study - something that was neither planned nor elicited by the research team - might be interpreted as an indication that bettors in recovery continue to ruminate about the chances of winning in sports betting and the alternative conclusions their story might have reached had it not been for their gambling disorder (i.e., counterfactual thinking). Sports bettors, the same as skill-based gamblers in general, struggle to make sense of their betting history and feel confused about the role their skills and knowledge played (Brevers et al., 2018; Cantinotti et al., 2004; Huberfeld et al., 2013; Khazaal et al., 2012). In general, gamblers undergoing 
treatment in the present study appeared to be aware that expressing thoughts about their gambling skills might be interpreted by therapists as an indication that they were not making progress and that they maintained invalid ideas about how gambling works. Intuitively, the interviewed gamblers appeared to be well aware that thinking 'winning is possible' is generally seen as a cognitive distortion by clinicians and scientists (Chrétien et al., 2017; Toneatto et al., 1997). However, the participants demonstrated through some of their verbalisations that they still retained a number of ideas about betting skills. Possibly, the existence of tipsters can reinforce such ideas. The bottom line is that such ideas are not inherently distorted but they are arguably distorted with respect to an individual diagnosed with gambling disorder. Betting on sports with a net profit is a rarity for any sports bettor in general, and in particular for those with a gambling disorder who typically have a history of consistent losses.

An important implication of the current findings is that psychological therapies for problems specific to skill-based gambling forms (such as sports betting) should find alternative cognitive strategies to substitute black and white ideas concerning the nature of gambling products. The 'all-is-random' persuasive strategy probably worked in the context of gambling markets largely characterised by slot machines, lotteries, and roulette games (Ladouceur et al., 2003) but fails to capture some of newer characteristics of gambling products.

In this regard, therapeutic approaches must take into consideration several - and sometimes conflicting - aspects of skill-based gambling. First, gambling products that incorporate skill-based features are ontologically different products than those completely based on chance. Second, gambling products solely based on skill would not be profitable 
for the industry because it would make them vulnerable to their customers' ability. Hence, the fundamental thing for therapists is to share with gamblers that, although some skill elements are present in sports betting, many others are in reality pseudo-skill elements that bookmakers put forward to enhance the illusion of control of bettors (Kwak et al., 2013; Lopez-Gonzalez et al., 2018). Third, the majority of sports bettors are not winners. In Spain, for instance, official data from the Ministry of Finance shows that $80 \%$ of online user accounts in the country are net losers or finish on a par with the bookmaker, with a minuscule percentage winning more than $€ 300$ a year (Direccion General de Ordenacion del Juego [Directorate General for the Regulation of Gambling], 2020). Consequently, the present authors contend that the cognitive distortions do not solely reside in thinking that sports betting is a skill-based game but that some sports bettors think they have greater skills than others (Browne et al., 2015; Mercier et al., 2018).

Tipsters represent one of a few possible professional job careers within the sports betting market. They make visible that making money with bets is viable and they embody the narrative of sports betting as a skill-based game. When slot machine or roulette gamblers seek help and get involved in a gambling therapy, ideally, they would progressively eliminate the perceptions that made them believe gambling was a realistic method of gaining money. However, during that process, they would not have to block contrasting evidence in the form of professional slot machine or roulette players that put into question the notion that winning is impossible. Although all sorts of gamblers might experience to some extent cognitive biases such as the availability of others' wins (i.e., witnessing gamblers near you winning; see Fortune \& Goodie, 2012; Griffiths, 1994), tipsters force bettors to integrate into their life story the alleged existence of long-run net winners, something they tried but were not able to do. 
As skill-based gambling gains popularity (Delfabbro et al., 2020), a skill production industry emerges in the shadow of skill-based gambling products. Drawing from the views of Cosgrave (2010), tipsters are arguably another element in a market environment dedicated to procuring 'safe risks' to consumers, risks that can be more or less mastered by sufficient preparation, study, and knowledge. The present authors argue that tipsters cohabit with media sport pundits, fantasy league providers, official data companies in partnerships with sports competitions, and other sport knowledge suppliers (LopezGonzalez \& Griffiths, 2018) in producing a sports betting market environment attractive enough for bettors to spend their money. If passively getting dreams to come true has traditionally been the selling proposition of chance-based gambling such as lotteries (Binde, 2007), new generations demand in their gambling products a more active role and an emphasis on skills, something bookmakers can only promise but not entirely grant unless they jeopardise their own business model.

The exploratory nature of this report makes it vulnerable to a number of limitations. First, participants were conveniently sampled given the inclusion criteria were met. Participants did not report why they chose to participate (or not) and the authors are unaware of the total pool of sports bettors eligible for the study. Given these circumstances, it is not possible to make claims regarding the selection biases of the sampling. Second, the strength of qualitative studies does not reside in their generalisability, and the present findings might not be representative of other sports betting contexts or countries. Third, online gamblers in recovery might be an especially vulnerable group to social desirability issues, particularly considering the private nature of the topics discussed and their awareness of the impact of their conduct (e.g., legal/criminal implications). Fourth, the 
focus group interview design is sensitive to recall biases. Fifth, the unequal distribution of participants between groups (range $=3-16$ ) might have overrepresented the opinions of some participants while underrepresenting others' in larger groups. Similarly, those bettors who reported not using tipster services provided no insights about the topic, and therefore, this paper cannot explain why some sports bettors use tipsters while others do not.

\section{Conclusion}

The present study is one of the first attempts to understand how professional sports betting experts (i.e., tipsters) can affect bettors in recovery. The evidence reported here illuminates the interaction between tipsters and sports bettors. Tipsters can be harmful for bettors undergoing treatment for gambling disorder because (as derived from participant data) tipsters can be viewed by bettors less as somebody who can help them and more as somebody they aspire to be. Sports bettors struggle to understand the role that chance and skill had in their gambling activity and, while being aware that development of a gambling disorder affected their gambling, wondered if their gambling history could have been different if they chose to become professional tipsters instead of gamblers. The findings of the present study contribute to the conceptualisation of skill-based gamblers in treatment and offers guidelines as to how to address the issue.

\section{References}

Angelini, G., \& De Angelis, L. (2019). Efficiency of online football betting markets. International Journal of Forecasting, 35(2), 712-721. https://doi.org/10.1016/j.ijforecast.2018.07.008

Binde, P. (2007). Selling dreams — causing nightmares? Journal of Gambling Issues, 20, 
167-192. https://doi.org/10.4309/jgi.2007.20.5

Brevers, D., Herremans, S. C., He, Q., Vanderhasselt, M. A., Petieau, M., Verdonck, D., ... \& Baeken, C. (2018). Facing temptation: The neural correlates of gambling availability during sports picture exposure. Cognitive, Affective and Behavioral Neuroscience, 18(4), 718-729. https://doi.org/10.3758/s13415-018-0599-z

Brown, A., \& Reade, J. J. (2019). The wisdom of amateur crowds: Evidence from an online community of sports tipsters. European Journal of Operational Research, 272(3), 1073-1081. https://doi.org/10.1016/j.ejor.2018.07.015

Browne, M., Rockloff, M.J., Blaszcynski, A., Allcock, C., \& Windross, A. (2015). Delusions of expertise: the high standard of proof needed to demonstrate skills at horserace handicapping. Journal of Gambling Studies, 31(1), 73-89. doi:10.1007/s10899-013-9420-7

Busby, M. (2017). Revealed: tipsters deliberately recommend losing bets to punters. The Guardian, September 1. Retrieved June 29, 2020, from: https://www.theguardian.com/society/2017/sep/01/revealed-tipsters-deliberatelyrecommend-losing-bets-to-punters

Cambridge Online Dictionary. (n.d.). Tipster. Cambridge University Press. Retrieved June 29, 2020, from: https://dictionary.cambridge.org/dictionary/english/tipster

Cantinotti, M., Ladouceur, R., \& Jacques, C. (2004). Sports betting: Can gamblers beat randomness? Psychology of Addictive Behaviors, 18(2), 143-147. https://doi.org/10.1037/0893-164X.18.2.143

Challét-Bouju, G., Hardouin, J. B., Lagadec, M., Burlacu, S., Valleur, M., Magalon, D., Fatséas, M., Cheréau-Boudet, I., Gorsane, M. A., JEU Group, Vénisse, J. L., \& Grall-Bronnec, M. (2016). Profiles of problem and non-problem gamblers, depending on their preferred gambling activity. Addiction Research \& Theory, 
24(3), 209-222. https://doi.org/10.3109/16066359.2015.1102895

Chrétien, M., Giroux, I., Goulet, A., Jacques, C., \& Bouchard, S. (2017). Cognitive restructuring of gambling-related thoughts: A systematic review. Addictive Behaviors, 75, 108-121. https://doi.org/10.1016/j.addbeh.2017.07.001

Cook, C. (2018). Bookmakers are urged to rethink closing down winning punters' accounts. Retrieved June 30, 2020, from The Guardian website: https://www.theguardian.com/sport/2018/jan/23/bookmakers-urged-to-rethinkclosing-punters-accounts

Cosgrave, J. F. (2010). Embedded addiction: The social production of gambling knowledge and the development of gambling markets. Canadian Journal of Sociology, 35(1), 113-134. https://doi.org/10.29173/cjs6135

Creswell, J. (2014). Research design: Qualitative, quantitative, and mixed methods approaches (4th ed.). Sage.

Deans, E. G., Thomas, S. L., Daube, M., \& Derevensky, J. (2017). The role of peer influences on the normalisation of sports wagering: a qualitative study of Australian men. Addiction Research \& Theory, 25(2), 103-113. https://doi.org/10.1080/16066359.2016.1205042

Dechant, K., \& Ellery, M. (2011). The effect of including a monetary motive item on the gambling motives questionnaire in a sample of moderate gamblers. Journal of Gambling Studies, 27(2), 331-344. https://doi.org/10.1007/s10899-010-9197-x

Delfabbro, P., King, D., \& Gainsbury, S. M. (2020). Understanding gambling and gaming skill and its implications for the convergence of gaming with electronic gaming machines. International Gambling Studies, 20(1), 171-183. https://doi.org/10.1080/14459795.2019.1662824

Direccion General de Ordenacion del Juego (2020). Report of online gamblers (2018). 
Retrieved June 29, 2020, from: https://www.ordenacionjuego.es/en/informejugador-online

Forrest, D., Goddard, J., \& Simmons, R. (2005). Odds-setters as forecasters: The case of English football. International Journal of Forecasting, 21(3), 551-564. https://doi.org/10.1016/j.ijforecast.2005.03.003

Forrest, D., \& Simmons, R. (2000). Forecasting sport: The behaviour and performance of football tipsters. International Journal of Forecasting, 16(3), 317-331. https://doi.org/10.1016/S0169-2070(00)00050-9

Fortune, E. E., \& Goodie, A. S. (2012). Cognitive distortions as a component and treatment focus of pathological gambling: A review. Psychology of Addictive Behaviors, 26(2), 298-310. https://doi.org/10.1037/a0026422

Gordon, R., \& Chapman, M. (2014). Brand community and sports betting in Australia. Victorian Responsible Gambling Foundation.

Griffiths, M. D. (1994). The role of cognitive bias and skill in fruit machine gambling. British Journal of Psychology, 85(3), 351-369. https://doi.org/10.1111/j.20448295.1994.tb02529.x

Hing, N., Vitartas, P., \& Lamont, M. (2017). Understanding persuasive attributes of sports betting advertisements: A conjoint analysis of selected elements. Journal of Behavioral Addictions, 6(4), 658-668. https://doi.org/10.1556/2006.6.2017.062

Huberfeld, R., Gersner, R., Rosenberg, O., Kotler, M., \& Dannon, P. N. (2013). Football gambling three arm-controlled study: Gamblers, amateurs and laypersons. Psychopathology, 46(1), 28-33. https://doi.org/10.1159/000338614

Jiménez-Murcia, S., Stinchfield, R., Álvarez-Moya, E., Jaurrieta, N., Bueno, B., Granero, R., ... Vallejo, J. (2009). Reliability, validity, and classification accuracy of a spanish translation of a measure of DSM-IV diagnostic criteria for pathological 
gambling. Journal of Gambling Studies, 25(1), 93-104. http://doi.org/10.1007/s10899-008-9104-x

Kaunitz, L., Zhong, S., \& Kreiner, J. (2017). Beating the bookies with their own numbers - and how the online sports betting market is rigged. ArXiv, 1710.02824 . https://arxiv.org/pdf/1710.02824.pdf

Khazaal, Y., Chatton, A., Billieux, J., Bizzini, L., Monney, G., Fresard, E., Thorens, G., Bondolfi, G., El-Guebaly, N., Zullino, D., \& Khan, R. (2012). Effects of expertise on football betting. Substance Abuse: Treatment, Prevention, and Policy, 7, 18. https://doi.org/10.1186/1747-597X-7-18

Kwak, D. H., Lee, J. S., \& Mahan III, J. E. (2013). Ad-evoked illusory judgments in Fantasy Sports participation: Effects of customization level and expert information. Journal of Sport Management, 27(5), 393-406. https://doi.org/10.1123/jsm.27.5.393

Ladouceur, R., Sylvain, C., Boutin, C., Lachance, S., Doucet, C., \& Leblond, J. (2003). Group therapy for pathological gamblers: A cognitive approach. Behaviour Research and Therapy, 41(5), 587-596. https://doi.org/10.1016/S00057967(02)00036-0

Lamont, M., Hing, N., \& Gainsbury, S. (2011). Gambling on sport sponsorship: A conceptual framework for research and regulatory review. Sport Management Review, 14(3), 246-257. https://doi.org/10.1016/j.smr.2011.04.004

Langer, E. (1975). The illusion of control. Journal of Personality and Social Psychology, 32(2), 311-328. https://doi.org/10.1037/0022-3514.32.2.311

Lopez-Gonzalez, H., Estévez, A., \& Griffiths, M. D. (2018). Controlling the illusion of control: a grounded theory of sports betting advertising in the UK. International Gambling Studies, 18(1), 39-55. https://doi.org/10.1080/14459795.2017.1377747 
Lopez-Gonzalez, H., \& Griffiths, M. D. (2018). Understanding the convergence of online sports betting markets. International Review for the Sociology of Sport, 53, 807-823. https://doi.org/doi:10.1177/1012690216680602

Lopez-Gonzalez, H., Griffiths, M. D., \& Estévez, A. (2020). Why some sports bettors think gambling addiction prevented them from becoming winners? A qualitative approach to understanding the role of knowledge in sports betting products. Journal of Gambling Studies. Epub ahead of print. https://doi.org/10.1007/s10899-020

Lopez-Gonzalez, H., \& Tulloch, C. D. (2015). Enhancing media sport consumption: Online gambling in European football. Media International Australia, 155, 130139.

MacKay, T. L., \& Hodgins, D. C. (2012). Cognitive distortions as a problem gambling risk factor in Internet gambling. International Gambling Studies, 12(2), 163-175. https://doi.org/10.1080/14459795.2011.648652

McCracken, C. (2014). Beating the odds in sports betting markets: English Premier League betting and the importance of in-game statistics [Princeton University]. $\begin{array}{llll}\text { Retrieved June } & 29, & \text { from: }\end{array}$ http://colemccracken.github.io/static/pdf/McCracken_Cole.pdf

Mercier, J., Sévigny, S., Jacques, C., Goulet, A., Cantinotti, M., \& Giroux1, I. (2018). Sports bettors: A systematic review. Journal of Gambling Issues, 38, 203-236. https://doi.org/10.4309/jgi.2018.38.11

Myrseth, H., Brunborg, G. S., \& Eidem, M. (2010). Differences in cognitive distortions between pathological and non-pathological gamblers with preferences for chance or skill games. Journal of Gambling Studies, 26(4), 561-569. https://doi.org/10.1007/s10899-010-9180-6

Newall, P. W. S. (2018). Behavioral complexity of British gambling advertising. 
Addiction Research \& Theory, 25(6), 505-511. https://doi.org/10.1080/16066359.2017.1287901

Orford, J. (2020). The gambling establishment: Challenging the power of the modern gambling industry and its allies. Routledge.

Petry, N. M. (2016). Gambling Disorder: The first officially recognized behavioral addiction. In N. M. Petry (Ed.), Behavioral addictions: DSM-5® and beyond (pp. 7-42). Oxford University Press.

Saldaña, J. (2009). The coding manual for qualitative researchers. Sage.

Sharman, S., Murphy, R., Turner, J. J. D., \& Roberts, A. (2019). Trends and patterns in UK treatment seeking gamblers: 2000-2015. Addictive Behaviors, 89(2), 51-56. https://doi.org/10.1016/j.addbeh.2018.09.009

Spann, M., \& Skiera, B. (2009). Sports forecasting: A comparison of the forecast accuracy of prediction markets, betting odds and tipsters. Journal of Forecasting, 28(1), 55-72. https://doi.org/10.1002/for.1091

Stevens, M., \& Young, M. (2010). Who plays what? participation profiles in chance versus skill-based gambling. Journal of Gambling Studies, 26(1), 89-103. https://doi.org/10.1007/s10899-009-9143-y

Toneatto, T., Blitz-Miller, T., Calderwood, K., Dragonetti, R., \& Tsanos, A. (1997). Cognitive distortions in heavy gambling. Journal of Gambling Studies, 13(3), 253266. https://doi.org/10.1023/A:1024983300428

Tong, A., Sainsbury, P., \& Craig, J. (2007). Consolidated criteria for reporting qualitative research (COREQ): a 32-item checklist for interviews and focus groups. International Journal for Quality in Health Care, 19(6), 349-357. https://doi.org/10.1093/intqhe/mzm042

Wilkinson, S. (2004). Focus groups. In G. M. Breakwell (Ed.), Doing social psychology 
research (pp. 344-376). The British Psychological Society and Blackwell Publishing Ltd. https://doi.org/10.1002/9780470776278.ch14

Wohl, M. J. A., Young, M. M., \& Hart, K. E. (2005). Untreated young gamblers with game-specific problems: Self-concept involving luck, gambling ecology and delay in seeking professional treatment. Addiction Research and Theory, 13(5), 445-459. https://doi.org/10.1080/16066350500168444

Woolley, R., Livingstone, C., Harrigan, K., \& Rintoul, A. (2013). House edge: Hold percentage and the cost of EGM gambling. International Gambling Studies, 13(3), 388-402. https://doi.org/10.1080/14459795.2013.829515 